\title{
Patient safety in work environments: perceptions of pediatric healthcare providers in Taiwan
}

\begin{abstract}
Background: Extensive research on the link between the organizational characteristics of the work environment and patient safety in a healthcare organization has been conducted; yet, only a few studies have concentrated on care providers in a pediatric unit.
\end{abstract}

Objectives: To determine the correlation between different work environment factors impacting patient safety in a pediatric care unit from the perspective of registered nurses working in these units.

Design: Cross-sectional design.

Data sources and methods: The study was conducted with 155 registered nurses from a pediatric unit in a medical center in Taiwan with the Chinese version of the Safety Attitudes Questionnaire (SAQ) 2014-2017.

Results: Teamwork climate, higher job satisfaction, and better working conditions are linked to positive perceptions of patient safety culture. Emotional exhaustion is negatively related to most dimensions of patient safety.

Conclusion: Teamwork climate, job satisfaction, working conditions, and emotional exhaustion were identified as critical factors impacting the patient safety climate. Implications for nursing or health policy: Investments to improve teamwork climate, job satisfaction, and working conditions and reduce emotional exhaustion may have a positive effect on patient safety in pediatric care units.

Keywords: Pediatric nurses; Teamwork climate; Job satisfaction; Safety attitudes questionnaire 


\section{Introduction}

In healthcare organizations, patient safety is defined as the prevention of accidental injury caused by errors of work (Institute of Medicine, 2004) and regarded as a top priority (Zheng et al., 2018). The work environment is "the set of characteristics that describes an organization and distinguishes it from other organizations; these characteristics should be relatively long-lasting and influence the conduct of members of the organization," as defined by Forehand and Gilmer (1964). Clearly, the design of the work environment influences patient safety outcomes, such as adverse events associated with the professionals serving in a healthcare organization (Laschinger \& Leiter, 2006). Unsafe healthcare such as medical errors includes errors in medical care, nosocomial infections, errors in teamwork, and diagnostic errors (Pham, Aswani, \& Rosen, 2012). Most of the errors in medical processes are directly or indirectly related to the care provider; consequently, the care provider plays a crucial role in ensuring patient safety (Groves, Meisenbach, \& Scott-Cawiezell, 2011).

Research on the connection between work environment and patient safety in health professionals is extensive. Aspects such as staff retention level, teamwork climate, the degree of exhaustion and emotional stress, working conditions, stress recognition, and the level of job satisfaction have been found to be associated with patient safety and related aspects such as patient mortality, healthcare-associated infection, medical errors, and adverse events (Alves \& Guirardello, 2016; Nantsupawat et al., 2017; Olds, Aiken, Cimiotti, \& Lake, 2017). Nurses in hospitals with better work environments have been found to strengthen their skills and have a greater awareness of near-miss incidents (Flynn, Liang, Dickson, Xie, \& Suh, 2012). Nurses in a deficient working environment, e.g., with improper working hours, are prone to the risk of medical errors or near-miss incidents (Wu et al., 2013). Thus, understanding the perception of nurses in the work environment is important for the healthcare organization to enhance patient safety.

To improve the caring process and enhance the degree of patient safety, it is essential to pay attention to what nurses perceive and need as a care provider (Fagan, Parker, \& Jackson, 2016; Allen, 2018). The illustrations are diverse, ranging from hardware and software training to becoming familiar with new technologies such as bar-code identification (Guffey \& Hyman, 2017), to improvements in the physical space (Farokhzadian, Nayeri, \& Borhani, 2015) and the use of aromatherapy as an instrument to reduce stress (Johnson et al., 2017). Funding support, equipment, and facilities also influence working conditions ( $\mathrm{Li}$ et al., 2018), along with the interventions of management in the organization of the care process (Saltzman et al., 2017).

The degree of resistance of disease between a child and an adult is distinct (Muttarak \& Dimitrova, 2019), and pediatric patients have been found to be infected 
more susceptibly than an adult to such an extent that the perceptions of health professionals' safety attitude is essential in the pediatric unit. Although there is a stream of research on neonatal intensive care units (Tawfik et al., 2016; Al-Hamdan, Manojlovich, \& Tanima, 2017; Profit et al., 2017), limited studies so far have investigated the effect of work environments on patient safety from the perspective of the care providers in the pediatric unit.

\section{Literature}

In a healthcare organization, a service process is designed and executed based on the patient safety strategy; therefore, the care provider is one of the most important components that determine the performance of patient safety (Mansour, 2015). They are on the frontline to provide services to patients; thus, the care provider's perception of patient safety in a work environment is essential for any healthcare organization to improve their overall patient safety performance. Also, the work environment is concerned as an organizational indicator that is relevant to patient safety (Olds et al., 2017). Thus, various dimensions in the work environment influence the conduct of care providers. Various attributes of the work environment have been considered in the literature, including those related to the physical environment, such as physical elements, challenge, freedom, support, coherence, threats in the work environment, and the effect of status quo (Hon et al., 2013), and those related to the social climate, such as employee participation, knowledge sharing, and procedural justice (Schepers \& Van den Berg, 2007).

In any healthcare organization, organizational characteristics in the work environment result in the behavior of the health professionals and the performance of organizations, such as patient mortality, healthcare-associated infection, adverse event, medical error, patient safety, patient safety culture, etc. Thus, for care providers, various attributes of patient safety have been considered in the literature and include job satisfaction, intention to stay, burnout, emotional distress, teamwork, safety climate, teamwork climate, perceptions of management, working conditions, stress recognition, and emotional exhaustion. Nantsupawat et al. (2017) indicated that burnout, job satisfaction, and intention to leave are important indicators to measure patient safety and patient care in Thai healthcare. Further, Olds et al. (2017) indicated that the results indicated that organizational characteristics such as safety climate and work environment in healthcare organizations are relative to patient mortality in the survey of non-federal hospitals, including California, Florida, Pennsylvania, and New Jersey in the United States. Occupational stress weakens the physical health and mental status of employees and has been found to be linked to fatigue, emotional distress, and exhaustion (Mosadeghrad, 2014). The freedom to express any opinion should be given 
when professionals detect mistakes in the service process (Profit et al., 2012).

In prior studies, considerable dimensions measuring work environments are discussed (Norman \& Sjetne, 2017). Three major directions concerned with the work environment are related to professional relationships, personal characteristics, and availability of resources. For example, collaborative relationships (Gregory et al., 2019), management support (Hayes, Douglas, \& Bonner, 2015), professional pride (Vikström \& Johansson, 2019), workload (Lee \& Kim, 2020), and working conditions (Dunstan $\&$ Coyer, 2020) are reviewed in the issue of work environments. Gregory et al. (2019) indicated an effective communication medical team in teamwork is critical for enhancing patient safety. Hayes et al. (2015) conducted an online survey in Australia and New Zealand and found that management support is an important organizational factor to make hemodialysis nurses satisfaction resulting in better performance in the work environment. A qualitative study from Vikström and Johansson (2019) indicated that the contributions that nurses benefit residents from their professional ability are correlated to professional pride in workplaces. Lee and Kim (2020) used the questionnaires to investigate the impact of stress factors on work performance for nurses from South Korea's hospitals. The results indicated that workload statistically significantly affects intention to leave. Inadequate staffing, which is related to nurseto-patient ratio, is one of the reasons that nurses suffer from a high workload. Dunstan and Coyer (2020) conducted the SAQ in intensive care units in two Australian hospitals. The results indicate that the scores of working conditions are statistically different among professions. In particular, working conditions that nurses possess with the lowest scores are essential for the healthcare organization to improve to benefit patient safety in hospitals.

Children are more susceptible to physical issues than adults in an ill environment (Muttarak \& Dimitrova, 2019). Thus, the care process and behavior of the care providers in the frontline are critical for patient safety in pediatric units. Additionally, nurses in pediatric units tend to suffer from occupational stress, as they are not only made to face the problems of their child patients but also the problems of their parents. The existence of burnout among the staff in a healthcare organization has been found to be associated with patient safety culture, which is a fundamental of care quality (Profit et al., 2014). In the safety issue of very low birth weight neonates, the degree of burnout and teamwork of the staff have been found to be associated with healthcareassociated infection rates (Tawfik et al., 2016; Profit et al., 2017). Care providers who suffer from emotional distress are more likely to be involved in adverse events in the Neonatal Intensive Care Unit; crucial factors to mitigate the likelihood and consequences of such events are the assistance from colleagues (Winning et al., 2018). With an improved work environment, job satisfaction for nurses was seen to increase 

showed the relationship among emotional exhaustion, safety climate, and job satisfaction from the perspective of nurses in a pediatric unit. In sum, the attributes measuring patient safety in the past research were diverse. Specifically, rare research investigates the health professionals' perception of patient safety in the work environment in a pediatric unit.

The SAQ is one of the most common methods to assess patient safety culture which is vital for the healthcare organization to understand the health professionals' perception of patient safety in the work environment. The SAQ developed by Sexton et al. (2006) in the United States has been used worldwide to assess the patient safety culture in healthcare organizations and characterized good psychometric properties and great internal consistency (Chi, Wu, Huang, \& Lee, 2017). Patient safety culture is defined as a "subset of organizational culture, which relates specifically to the values and beliefs concerning patient safety within healthcare organizations" (Feng, Bobay, \& Weiss, 2008). It is constructed by various dimensions and results in different behaviors of patient safety (Sexton et al., 2006). Understanding the importance of work environment factors in the SAQ helps decision-makers improve patient safety in healthcare organizations (Lee, Weng, Stanworth, Hsieh, \& Wu, 2015). In recent studies, patient safety in several healthcare-related workplaces such as intensive care units (Dunstan \& Coyer, 2020), ambulatory practices (Miller et al., 2019), inpatient mental health services (Dickens, Salamonson, Ramjan, Steel, \& Everett, 2019), the entire hospital (Lee, Tzeng, \& Chiang, 2019a; Lee, Huang, Wu, Hsueh, \& Wu, 2019b; Pavan et al., 2019; O’Leary et al., 2019), home nursing (Bondevik, Hofoss, Husebø, \& Deilkås, 2019) is assessed by the SAQ.

In Taiwan, based on the SAQ (short form 2006), the Joint Commission of Taiwan developed the Chinese version of the SAQ to assess the patient safety culture in healthcare organizations on a yearly basis (Chi et al., 2017; Lee, Shieh, Huang, Wang, \& Wu, 2017a; Lee, Huang, Hsu, \& Wu, 2016). In 2008, the first Chinese version of the SAQ was launched, with 6 dimensions and 30 questions, based on the short form of the SAQ developed by the Joint Commission of Taiwan (Chi et al., 2017; Lee et al., 2017a). In 2014, three hospital-level aspects of safety culture from the Agency for Healthcare Research and Quality, which were originally included in the previous version, were removed. Two dimensions, emotional exhaustion and work-life balance, were added (Chi et al., 2017). Thus, the current Chinese version of the SAQ in the survey has 8 dimensions and 46 questions. In fact, since 2008, the Chinese version of the SAQ has been regarded as the official questionnaire to assess the patient safety culture in Taiwan because both the survey results and the original data set need to be submitted electronically to the Joint Commission of Taiwan through the website under the current 
medical system in Taiwan (Lee et al., 2017b). Thus, this study investigates a survey by using the Chinese version of the SAQ in one of the best medical centers to evaluate health professionals' perception of patient safety in a pediatric unit.

In sum, prior studies address various issues such as professional relationship (Gregory et al., 2019; Hayes et al., 2015), personal characteristics (Vikström \& Johansson, 2019; Lee \& Kim, 2020), and availability of resources (Dunstan \& Coyer, 2020) showing that good work environments directly or indirectly benefit quality of care. In a study of Shaheen, El-Hneiti, Albqoor, \& Ahmad (2019), the factors of work environments, including work stress, work-related exhaustion, participation management, and skills development, do not significantly impact the quality of care for nurses who provide care for adults. However, prior research rarely investigates the relationships between the work environment and patient safety from the perceptions of pediatric nurses based on the SAQ.

To the best of our knowledge, the only studies investigating the perception of pediatric nurses on work environment factors are those of Alves and Guirardello (2016) and Alves et al. (2016), who showed the relationship between emotional exhaustion, safety climate, and job satisfaction in pediatric units in Brazil. Our study was carried out in the pediatric unit of a medical center in Taiwan. Patient safety issues are gaining increased attention in many Taiwanese hospitals (Ministry of Health and Welfare, 2019); yet, to the best of our knowledge, this is the first study that is focusing on the link between organizational factors and patient safety for a pediatric unit. Our study differs from the work of Alves and Guirardello (2016), as we investigated the perceptions of pediatric nurses from a more comprehensive view based on the SAQ, focusing on the predictive effects of the following six dimensions: 1) emotional exhaustion, 2) job satisfaction, 3) teamwork climate, 4) stress recognition, 5) perceptions of management, and 6) working conditions.

\section{Study aim}

This study aims to investigate the perceptions of registered nurses about patient safety in pediatric work environments.

\section{Methods}

\section{Study design and sample}

The selected case hospital is ranked as one of the best medical centers in Taiwan and contains more than 35 divisions with 1500 employees in total, providing 700 hospital beds and clinical education and training to health professionals. The pediatric nurses were annually requested to participate in the survey by using the latest Chinese version of the SAQ (SAQ, see Table 1) in the 2014-2017 period. Thus, an effective 
number of questionnaires for pediatric nurses were obtained using the internal survey data conducted in this medical center. This study has been approved by the institutional review board. The clinical trial approval certificate (ethic statement) was approved by Cheng Ching General Hospital in Taichung City, Taiwan.

All the respondents were considered individually as one sample. In the work environment, each nurse has to take care of various patients with different psychometric properties when executing missions. Thus, the same nurse has been considered as an independent individual instead of the same individual when responding to the questionnaire each year. There is a constant interval to distribute the questionnaires every year; the questionnaires are taken as one sample.

\section{Measure}

Based on the Sexton et al.'s (2006) SAQ, the Joint Commission of Taiwan has incorporated the Maslach Burnout Inventory-Human Services Survey (MBI-HSS) to completely assess the attitudes of hospital staff toward a better patient safety culture. The emotional exhaustion dimension from the MBI-HSS and work-life balance were integrated into the questionnaire. Thus, the Chinese version of the SAQ questionnaire contains 46 questions, grouped into 8 dimensions: teamwork climate (questions 1 to 6), safety climate (questions 7 to 13), job satisfaction (questions 14 to 18), stress recognition (measured through reverse-scored questions 19, 21, 25, and 26); perceptions of management (questions 27 to 30), working conditions (questions 31 to 34), emotional exhaustion (measured through reverse-scored questions 20, 22, 23, 24, $35,36,37,38$, and 39), and work-life balance (questions 40 to 46).

The Chinese version of the SAQ has been confirmed to be reliable and valid by the results of Huang, Wu, \& Lee (2018a) and Wu, Lee, \& Huang (2019) in order to better understand the perceptions of physicians and nurses toward patient safety culture. The Cronbach's alphas for the dimensions of the SAQ ranged around 0.760 to 0.941 . Each question in each dimension was assessed using a five-point Likert scale $(1=$ Strongly Disagree and $5=$ Strongly Agree). Work-life balance was excluded since it is a four-point frequency scale different from an interval scale. Sexton et al. (2018) and Sexton et al. (2017) demonstrate work-life balance has a weak correlation to safety climate. Based on the aforementioned studies, work-life balance was removed from the analysis.

\section{Insert Table 1 here}

\section{Data Analysis}


This following section outlines the assessment of statistical analysis used to evaluate the dimensions of patient safety. The descriptive statistics were initially calculated to provide the demographic information of pediatric nurses and the scores for each of patient safety dimensions. Next, we used the Pearson's correlation coefficient in SPSS 22.0 to examine the strength of the linear relationship between any two continuous variables of seven patient safety dimensions. Specifically, the correlation relationships between safety climate and the other six patient safety dimensions (i.e., teamwork climate, job satisfaction, stress recognition, perceptions of management, working conditions, and emotional exhaustion) were investigated (Cohen, Cohen, West, \& Aiken, 2013).

After validating the direct and strength of patient safety dimensions, linear regression with forward selection was used to identify the essential dimension(s) that affect safety climate from the perspective of pediatric nurses. Linear regression with forward selection starts with an empty set and adds an attribute one at a time continually. At each step, only the variable which gives the highest correlation with the dependent variable is added into the selection (Chi, Huang, Lee, \& Wu, 2019). That is, variables that have greater theoretical importance are entered first. It is worth mentioning that an interaction effect of independent variables is unable to be included in the forward selection approach, but the decision-maker allows to clarify which variable has a greater impact directly on the dependent variable (Karagiannopoulos, Anyfantis, Kotsiantis, \& Pintelas, 2007; Cheng, Lee, Huang, \& Wu, 2020).

The criteria of adding variable(s) into a linear regression model is implemented: a variable in the probability of $\mathrm{F}$ less than 0.05 is considered to enter the linear regression model until none of the variables statistically significantly improves the model. To this end, six dimensions, including teamwork climate, job satisfaction, stress recognition, perceptions of management, working conditions, and emotional exhaustion, are the independent variables, whereas the safety climate is the dependent variable in the Chinese version of the SAQ.

The work experience in an organization and age were used as contextual variables to test for possible nonresponse bias. Results indicated no significant difference at a 0.05 significance level for the two contextual variables. Therefore, non-responsive bias was not a significant concern in this study.

\section{Results}

Descriptive statistics of the respondents' demographic characteristics are provided in Table 2. The sample profile demonstrated that most respondents were female (99.4\%), age ranged from 31 to 40 years $(38.1 \%)$, and education of the bachelor $(89.7 \%)$. Around three-fourths of respondents with relevant working experiences were 
employed more than five years in the hospital.

\section{Insert Table 2 here}

Among the 8 dimensions surveyed in the questionnaire (see Table 1), we considered the safety climate (SC) as the dependent variable and studied the predictive effect of the following 6 independent variables: 1) emotional exhaustion (EE), 2) job satisfaction (JS), 3) teamwork climate (TC), 4) stress recognition (SR), 5) perceptions of management (PM), and 6) working conditions (WC). We did not include the impact of work-life balance, as this was measured on a frequency scale. The scores for each of the six dimensions were calculated by summing the scores of the items measuring that particular dimension.

\section{Insert Table 3 here}

As shown in Table 3, the results of the statistical analysis demonstrated that safety climate (average value is 26.59) has the highest average value, whereas stress recognition (average value is 14.38) has the lowest average value. The Cronbach's $\alpha$ values of all seven dimensions were found to be greater than 0.60 , which demonstrates acceptable internal consistency. Overall, the dimensions of patient safety represented satisfactory outcomes except for the lowest mean percentage of emotional exhaustion (54\%). In particular, the results indicated that the emotional exhaustion has a higher standard deviation than the other patient safety dimensions. Analysis of variance is further employed to test if nurses have different perceptions in emotional exhaustion. Table 4 illustrated that nurses aged 21-30 and 31-40 have a significantly lower degree of emotional exhaustion than those aged 51-60 statistically. Thus, the degree of emotional exhaustion may vary from age to age.

\section{Insert Table 4 here}

Table 5 shows the Pearson's correlation coefficients between the dimensions. The results demonstrated the perceptions of management were significantly correlated with working conditions and job satisfaction: the more management support the nurses felt, the higher the perception of working conditions and job satisfaction would be. Safety climate was found to be significantly correlated to teamwork climate. In addition, emotional exhaustion was found to be significantly negatively correlated with most dimensions of patient safety culture. When employees have a higher degree of emotional exhaustion, they tend to feel less satisfaction in job satisfaction, teamwork 
climate, perceptions of management, and working conditions.

\section{Insert Table 5 here}

The result for regression analysis is shown in Table 6. The approach with forward selection confirmed that teamwork climate, job satisfaction, and working conditions can predict safety climate; the other dimensions were found to have coefficients that did not differ significantly from 0.05 . Teamwork climate $(\beta=0.505)$ has the most positive effect on safety climate, followed by job satisfaction $(\beta=0.208)$ and working conditions with $\beta=0.204$. The more the nurses are satisfied with job and working conditions, the better the safety climate is perceived to be.

\section{Insert Table 6 here}

\section{Discussion}

This study aims to assess factors that have significantly affected patient safety in a work environment from the perspective of registered nurses working in the pediatric care unit of a medical center in Taiwan. The discussions of findings are given below.

First, the Pearson's correlation coefficient results demonstrated that emotional exhaustion is negatively related to safety climate. Similarly, the level of emotional exhaustion is negatively correlated with job satisfaction, teamwork climate, perceptions of management, and working conditions, respectively. Studies conducted in pediatric care units have commonly illustrated high levels of emotional exhaustion among nurses (Profit et al., 2014; Alves \& Guirardello, 2016; dos Santos Alves, da Silva, \& de Brito Guirardello, 2017). Indeed, the workload for nurses is high: with an average nursepatient ratio reaching 1:9.8 in the case hospital in 2019, Taiwan performed much worse than the international ratio of 1:6 (Ministry of Health and Welfare, 2019). Existing studies have already emphasized the burnout risks among nurses in Taiwan, which leads to adverse consequences such as medical errors, increased personnel turnover, absenteeism, shortage of staff, and failure to meet patient needs (Huang, Wu, Lee, Wu, $\&$ Lin, 2018b). As these negative outcomes threaten the safety of patients, we suggest tracking the level of emotional exhaustion, for instance, by implementing Employee Assistance Programs (EAP) that regularly monitor potential factors affecting nurses' productivity (such as working pressure, interpersonal relations, and work deployment). Moreover, stable recruitment programs and standard handoff systems should be implemented to decrease the high nurse-patient ratio and mitigate the occurrence of medical errors and mistakes during shifts.

Second, teamwork climate was shown to have the most positive impact on safety 

(2017) and Gabrani, Hoxha, Simaku, \& Gabrani (2015), who showed as the teamwork of hospital staff (e.g. physicians and nurses) strengthens, the safety climate increases. Indeed, a strong teamwork climate in hospitals contributes to the promotion of an environment that enables the delivery of safe care and therefore, ensures the enhancement of patient safety. This positive relationship has been mainly attributed to better communication, coordination, collaboration between nurses and physicians within the units, and participation at bedside rounds (Abu-El-Noor et al., 2017; Jiménez, Swartz, \& McCorkle, 2018). Thus, hospital managers should encourage and incentivize cooperation between nurses and physicians, promote awareness of the importance of patient safety regularly, and support open dialogue and regular communication about patient safety issues in the units.

Third, our results revealed that working conditions influence the perception of patient safety. This is consistent with the study in Huang et al. (2018a). In general, nurses face a variety of challenges during work time, such as high time pressure, multitasking, and staffing shortages. Nurses in a pediatric unit need to pay more attention to children's patients rather than to adult patients in other units. In a work environment, a high workload implies nurses possess fewer resources in the workplace (Fagerström, Kinnunen, \& Saarela, 2018). Resources such as training programs for nurses can help avoid outcomes such as burnout and the perceived quality of care (Paguio \& Doris, 2019). General respect for the health and wellbeing of nurses is a key part of the working conditions (Gershon et al., 2007). The present study confirms that human resource management improves the patient safety climate, for instance by employing sufficient staff, by implementing a more rational salary system with performance-based bonuses, and by providing training programs for new personnel. The latter is particularly important, as inconsistent procedures may impact patient safety and wellbeing; e.g., premedication practices under endotracheal intubation in Hatch et al. (2016) and Foglia et al. (2015).

Last but not least, the results show that safety climate is positively impacted by job satisfaction. Nurses with more work experience may represent higher consciousness about patient safety (Alves \& Guirardello, 2016; dos Santos Alves et al., 2017; Roney $\&$ Acri, 2018). As suggested by the literature, job satisfaction can be strengthened, for instance, by implementing effective performance appraisal mechanisms, facilitating transparent communications between the nurses and patients, improving communications in adverse events (Wagner et al., 2018; Jiménez, Swartz, \& McCorkle, 2018), and enhancing the sense of belonging and participation (which can strengthen nurses' sense of belonging to the units and/or hospitals). Moreover, the transformational leadership style of the administrators and/or supervisors on the 

Nurses' empowerment may be influenced by the perception that the hospital cares about its nurses' wellbeing and that their work is valued. Empowering nurses may increase job satisfaction and intensify patient safety quality (Boamah, Laschinger, Wong, \& Clarke, 2018; Roney \& Acri, 2018).

\section{Implications for Nursing and Health Policy}

When nurses are satisfied with their work environment, negative perceptions of their work are reduced (Liu, Aungsuroch, \& Yunibhand, 2016) and consequently, patient safety is enhanced in healthcare. Interventions for improving nurses' perception of emotional exhaustion, job satisfaction, working conditions, and teamwork climate are needed to provide a better work environment and, thus, effectively promote patient safety.

Designing mechanisms that facilitate transparent communications between personnel and patients can avoid adverse events and thus strengthen job satisfaction in patient safety climate. A regular reward should also be awarded to nurses to recognize their outstanding performance so that they feel appreciated at work and to enhance their job satisfaction. Creating a sufficient workplace might be a good way to increase work pleasure and performance.

Hospital managers have the responsibility to encourage and incentivize interactions between personnel through appropriate activities improving the teamwork climate. The establishment of Quality Control Circle (QCC) or Huddle Observational Tool (HOT) can motivate the enthusiasm of nursing staff to participate in gaining professional knowledge and member-interactive activities, which in turn strengthens cooperative teamwork and communication skills. Providing a variety of communication channels such as seminars, staff suggestion boxes, and consultations to communicate with nurses can promote mutual understanding between nursing members and units in the hospital, which is favorable to patient safety work and can create a harmonious atmosphere of cross-unit teamwork.

Support and encouragement for nurses from hospital managers are important for providing better working conditions. Implementations could include adjusting the nursing salary structure appropriately as well as creating a self-development platform. Similarly, training programs through hospital seminars based on specific professional and the knowledge of patient safety can have a positive effect on working conditions. Additionally, designing interventions that allow for the transformational leadership style as well as empowerment on varying classifications of nursing personnel may be a more effective strategy for promoting nurses' attitudes and behaviors toward patient safety. 
Policies and strategies including maintaining an adequate nurse-patient ratio are important for nurses to avoid exhaustion and to ensure nurses have plenty of energy and enthusiasm to deliver professional care to patients. Ensuring the status of nurses' physical and mental exhaustion by closely monitoring their productiveness is essentially important. The development of a systemic mentorship is critical in exchanging professional knowledge, skills, and valuable experience among nurses, thus reducing the overall stress and exhaustion built up in the units.

\section{Limitations}

Our research has limitations. The respondents were registered nurses from the pediatric care unit at a medical center. Thus, the results may not generalize to other institutions such as regional and/or district hospitals. Extending the study to other healthcare organizations could improve the scope of the study. Future studies on patient safety could also examine the perspective of other staff types, such as technicians, pharmacists, etc.

\section{Conclusions}

The results suggest that investments that facilitate teamwork climate, job satisfaction, and working conditions can contribute substantially to improvements in the safety climate. Moreover, the negative effect of emotional exhaustion on the safety climate was identified in the current study. Related activities that allowed employees to increase the degree of responsibility for their jobs were found to be helpful and should be promoted by the organization (Alves \& Guirardello, 2016). To better promote patient safety culture in pediatric units, implementations related to the work environment variables, such as teamwork climate, job satisfaction, stress recognition, perceptions of management, working conditions, and emotional exhaustion, analyzed in this study should be given a high priority in nursing interventions.

\section{Reference}

1. Abu-El-Noor, N. I., Hamdan, M. A., Abu-El-Noor, M. K., Radwan, A. K. S., \& Alshaer, A. A. (2017). Safety culture in neonatal intensive care units in the Gaza strip, Palestine: a need for policy change. Journal of Pediatric Nursing, 33, 76-82. https://doi.org/10.1016/j.pedn.2016.12.016

2. AlHamdan, Z., Manojlovich, M., \& Tanima, B. (2017). Jordanian nursing work environments, intent to stay, and job satisfaction. Journal of Nursing Scholarship, 49(1), 103-110. https://doi.org/10.1111/jnu.12265

3. Allen, D. (2018). Translational Mobilisation Theory: a new paradigm for 
understanding the organisational elements of nursing work. International journal of Nursing Studies, 79, 36-42. https://doi.org/10.1016/j.ijnurstu.2017.10.010

4. Alves, D. F. S., \& Guirardello, E. B. (2016a). Safety climate, emotional exhaustion and job satisfaction among Brazilian pediatric professional nurses. International Nursing Review, 63(3), 328-335. https://doi.org/10.1111/inr.12276

5. Alves, D. F. S., \& Guirardello, E. D. B. (2016b). Nursing work environment, patient safety and quality of care in pediatric hospital. Revista gaucha de enfermagem, 37(2), e58817. http://dx.doi.org/10.1590/1983-1447.2016.02.58817

6. Boamah, S. A., Laschinger, H. K. S., Wong, C., \& Clarke, S. (2018). Effect of transformational leadership on job satisfaction and patient safety outcomes. Nursing Outlook, 66(2), 180-189. https://doi.org/10.1016/j.outlook.2017.10.004

7. Bondevik, G. T., Hofoss, D., Husebø, B. S., \& Deilkås, E. C. T. (2019). The safety attitudes questionnaire-ambulatory version: psychometric properties of the Norwegian version for nursing homes. BMC health services research, 19, 423. https://doi.org/10.1186/s12913-019-4244-5

8. Cheng, C., Lee, Y. C., Huang, \& Wu, H. H. (2020). Assessing the medical staff's overall satisfaction of patient safety culture from a regional teaching hospital in Taiwan. Journal of Testing and Evaluation, 48 (in press). https://doi.org/10.1520/JTE20180116

9. Chi, C. Y., Huang, C. H., Lee, Y. C., \& Wu, H. H. (2019). Critical demographic variables on affecting Patient safety culture from medical staffs' viewpoints. Engineering Letters, 27(2), 76-83.

10. Chi, C. Y., Wu, H. H., Huang, C. H., \& Lee, Y. C. (2017). Using linear regression to identify critical demographic variables affecting patient safety culture from viewpoints of physicians and nurses. Hospital Practice and Research, 2(2), 47-53. http://dx.doi.org/10.15171/HPR.2017.12

11. Cohen, J., Cohen, P., West, S. G., \& Aiken, L. S. (2013). Applied multiple regression/correlation analysis for the behavioral sciences. London: Lawrence Erlbaum Associates.

12. Dickens, G. L., Salamonson, Y., Ramjan, L., Steel, K., \& Everett, B. (2019). Safety attitudes, perceived organizational culture and knowledge of the physiologically deteriorating patient among mental health nurses: cross-sectional, correlational study. International Journal of Mental Health Nursing, 28(6), 1347-1362. https://doi.org/10.1111/inm.12649

13. dos Santos Alves, D. F., da Silva, D., \& de Brito Guirardello, E. (2016). Nursing practice environment, job outcomes and safety climate: a structural equation modelling analysis. Journal of Nursing Management, 25(1), 46-55. 
https://doi.org/10.1111/jonm.12427

14. Dunstan, E., \& Coyer, F. (2020). Safety culture in two metropolitan Australian tertiary hospital intensive care units: a cross-sectional survey. Australian Critical Care, 33(1), 4-11. https://doi.org/10.1016/j.aucc.2018.11.069

15. Fagan, A., Parker, V., \& Jackson, D. (2016). A concept analysis of undergraduate nursing students speaking up for patient safety in the patient care environment. Journal of Advanced Nursing, 72(10), 2346-2357. https://doi.org/10.1111/jan.13028

16. Fagerström, L., Kinnunen, M., \& Saarela, J. (2018). Nursing workload, patient safety incidents and mortality: an observational study from Finland. BMJ Open, 8(4), e016367. http://dx.doi.org/10.1136/bmjopen-2017-016367

17. Farokhzadian, J., Nayeri, N. D., \& Borhani, F. (2015). Rocky milieu: challenges of effective integration of clinical risk management into hospitals in Iran. International Journal of Qualitative Studies on Health and Well-being, 10(1), 27040. https://doi.org/10.3402/qhw.v10.27040

18. Feng, X., Bobay, K., \& Weiss, M. (2008). Patient safety culture in nursing: a dimensional concept analysis. Journal of Advanced Nursing, 63(3), 310-319. https://doi.org/10.1111/j.1365-2648.2008.04728.x

19. Flynn, L., Liang, Y., Dickson, G. L., Xie, M., \& Suh, D. C. (2012). Nurses' practice environments, error interception practices, and inpatient medication errors. Journal of Nursing Scholarship, 44(2), 180-186. https://doi.org/10.1111/j.15475069.2012.01443.x

20. Foglia, E. E., Ades, A., Napolitano, N., Leffelman, J., Nadkarni, V., \& Nishisaki, A. (2015). Factors associated with adverse events during tracheal intubation in the NICU. Neonatology, 108(1), 23-29. https://doi.org/10.1159/000381252

21. Forehand, G. A, \& Gilmer, B. V. (1964). Environmental variation in studies of organizational behavior. Psychological Bulletin, 62(6), 361-382. https://doi.org/10.1037/h0045960

22. Gabrani, A., Hoxha, A., Simaku, A., \& Gabrani, J. C. (2015). Application of the Safety Attitudes Questionnaire (SAQ) in Albanian hospitals: a cross-sectional study. BMJ Open, 5(4), e006528. http://dx.doi.org/10.1136/bmjopen-2014$\underline{006528}$

23. Gershon, R. R., Stone, P. W., Zeltser, M., Faucett, J., Macdavitt, K., \& Chou, S. S. (2007). Organizational climate and nurse health outcomes in the United States: a systematic review. Industrial Health, 45(5), 622-636. https://doi.org/10.2486/indhealth.45.622

24. Gregory, M. E., Hughes, A. M., Benishek, L. E., Sonesh, S. C., Lazzara, E. H., Woodard, L. D., \& Salas, E. (2019). Toward the development of the perfect 
medical team: critical components for adaptation. Journal of Patient Safety. doi: 10.1097/PTS.0000000000000598

25. Groves, P. S., Meisenbach, R. J., \& Scott-Cawiezell, J. (2011). Keeping patients safe in healthcare organizations: a structuration theory of safety culture. Journal of Advanced Nursing, 67(8), 1846-1855. https://doi.org/10.1111/j.13652648.2011.05619.x

26. Guffey, P., \& Hyman, D. (2017). Principles of Patient Safety in Pediatric $\mathrm{Hem} / \mathrm{Onc} / \mathrm{HSCT}$. In Patient Safety and Quality in Pediatric Hematology/Oncology and Stem Cell Transplantation (pp. 123-140). Springer, Cham.

27. Hatch, L. D., Grubb, P. H., Lea, A. S., Walsh, W. F., Markham, M. H., Whitney, G. M., Slaughter, J. C., Stark, A. R., \& Ely, E. W. (2016). Endotracheal intubation in neonates: a prospective study of adverse safety events in 162 infants. The Journal of Pediatrics, 168, 62-66. https://doi.org/10.1016/j.jpeds.2015.09.077

28. Hayes, B., Douglas, C., \& Bonner, A. (2015). Work environment, job satisfaction, stress and burnout among haemodialysis nurses. Journal of Nursing Management, 23(5), 588-598. https://doi.org/10.1111/jonm.12184

29. Hon, A. H., Chan, W. W., \& Lu, L. (2013). Overcoming work-related stress and promoting employee creativity in hotel industry: the role of task feedback from supervisor. International Journal of Hospitality Management, 33, 416-424. https://doi.org/10.1016/j.ijhm.2012.11.001

30. Huang, C. H., Wu, H. H., \& Lee, Y. C. (2018a). The perceptions of patient safety culture: A difference between physicians and nurses in Taiwan. Applied Nursing Research, 40, 39-44. https://doi.org/10.1016/j.apnr.2017.12.010

31. Huang, C. H., Wu, H. H., Lee, Y. C., Wu, C. F., Lin, M. C. (2018b). What we should know about patient safety culture: An empirical investigation of viewpoints from four categories of hospital staffs in Taiwan. International Journal of Management, Economics and Social Sciences, 7, 73-84.

32. Institute of Medicine. (2004). Patient Safety. Washington, DC: National Academy Press.

33. Jiménez, R. A., Swartz, M., \& McCorkle, R. (2018). Improving quality through nursing participation at bedside rounds in a pediatric acute care unit: a pilot project. Journal of Pediatric Nursing, 43, 45-55. https://doi.org/10.1016/j.pedn.2018.08.010

34. Johnson, K., West, T., Diana, S., Todd, J., Haynes, B., Bernhardt, J., \& Johnson, R. (2017). Use of aromatherapy to promote a therapeutic nurse environment. Intensive and Critical Care Nursing, 40, 18-25. https://doi.org/10.1016/j.iccn.2017.01.006

35. Karagiannopoulos, M., Anyfantis, D., Kotsiantis, S. B., \& Pintelas, P. E., (2007). 
Feature selection for regression problems. Proceedings of the 8th Hellenic European Research on Computer Mathematics \& its Applications. Athens, Greece: 20-22.

36. Laschinger, H. K. S., \& Leiter, M. P. (2006). The impact of nursing work environments on patient safety outcomes: The mediating role of burnout engagement. The Journal of Nursing Administration, 36(5), 259-267. https://doi.org/10.1097/00005110-200605000-00019

37. Lee Y. C., Weng, S. J., Stanworth, J. O., Hsieh, L. P., \& Wu, H. H., (2015). Identifying critical dimensions and causal relationships of patient safety culture in Taiwan. Journal of Medical Imaging and Health Informatics, 5(5), 995-1000. https://doi.org/10.1166/jmihi.2015.1482

38. Lee, E. K., \& Kim, J. S. (2020). Nursing stress factors affecting turnover intention among hospital nurses. International Journal of Nursing Practice, e12819. https://doi.org/10.1111/ijn.12819

39. Lee, T. S. H., Tzeng, W. C., \& Chiang, H. H. (2019a). Impact of Coping Strategies on Nurses' Well-Being and Practice. Journal of Nursing Scholarship, 51(2), 195 204. https://doi.org/10.1111/jnu.12467

40. Lee, Y. C., Huang, C. H., Hsu, C. Y., \& Wu, H. H. (2016). A longitudinal study of assessing the patient safety culture from nurses' viewpoints based on the safety attitudes questionnaire in Taiwan. International Journal of Innovation, Management and Technology, 7(6), 266-271. https://doi.org/10.18178/ijimt.2016.7.6.685

41. Lee, Y. C., Huang, C. H., Wu, C. F., Hsueh, H. W., \& Wu, H. H. (2019b). A longitudinal study of identifying critical variables influencing patient safety culture from nurses' viewpoints in Taiwan. Journal of Testing and Evaluation, 47(5), 3387-3398. https://doi.org/10.1520/JTE20180060

42. Lee, Y. C., Shieh, J. I, Huang, C. H., Wang, C. Y., \& Wu, H. H. (2017a). Analyzing patient safety culture from viewpoints of physicians and nurses - A case of a regional teaching hospital in Taiwan. Journal for Healthcare Quality, 39(5), 294306. https://doi.org/10.1097/JHQ.0000000000000065

43. Lee, Y. C., Weng, S. J., Huang, C. H., Hsieh, W. L., Hsieh, L. P., \& Wu, H. H., (2017b). A longitudinal study of identifying critical factors of patient safety culture in Taiwan. Journal of Testing and Evaluation, 45(3), 1029-1044. https://doi.org/10.1520/JTE20140444

44. Li, Y., Zhao, Y., Hao, Y., Jiao, M., Ma, H., Teng, B., Yang, K., Sun, T. B., Wu, Q. H., \& Qiao, H. (2018). Perceptions of patient safety culture among healthcare employees in tertiary hospitals of Heilongjiang province in northern China: a crosssectional study. International Journal for Quality in Health Care, 30(8), 618-623. 
https://doi.org/10.1093/intqhe/mzy084

45. Liu, Y., Aungsuroch, Y., \& Yunibhand, J. (2016). Job satisfaction in nursing: a concept analysis study. International Nursing Review, 63(1), 84-91. https://doi.org/10.1111/inr.12215

46. Mansour, M. (2015). Factor analysis of nursing students' perception of patient safety education. Nurse Education Today, 35(1), 32-37. https://doi.org/10.1016/j.nedt.2014.04.020

47. Miller, N., Bhowmik, S., Ezinwa, M., Yang, T., Schrock, S., Bitzel, D., \& McGuire, M. J. (2019). The relationship between safety culture and voluntary event reporting in a large regional ambulatory care group. Journal of patient safety, 15(4), e48-e51. DOI: 10.1097/PTS.0000000000000337

48. Ministry of Health and Welfare. (2019). The lists of nurse-patient ratio for hospitals in Taiwan in 2019. Retrieved from: https://www.nhi.gov.tw/Content_List.aspx?n=4037A32CDEF1DDCF\&topn=CD A985A80C0DE710

49. Mohammad Mosadeghrad, A., (2014). Occupational stress and its consequences: Implications for health policy and management. Leadership in Health Services. 27(3), 224-239. https://doi.org/10.1108/LHS-07-2013-0032

50. Muttarak, R., \& Dimitrova, A. (2019). Climate change and seasonal floods: potential long-term nutritional consequences for children in Kerala, India. BMJ Global Health, 4(2), e001215. http://dx.doi.org/10.1136/bmjgh-2018-001215

51. Nantsupawat, A., Kunaviktikul, W., Nantsupawat, R., Wichaikhum, O. A., Thienthong, H., \& Poghosyan, L. (2017). Effects of nurse work environment on job dissatisfaction, burnout, intention to leave. International Nursing Review, 64(1), 91-98. https://doi.org/10.1111/inr.12342

52. Norman, R. M., \& Sjetne, I. S. (2017). Measuring nurses' perception of work environment: a scoping review of questionnaires. BMC nursing, 16, 66. https://doi.org/10.1186/s12912-017-0256-9

53. O’Leary, K. J., Johnson, J. K., Manojlovich, M., Goldstein, J. D., Lee, J., \& Williams, M. V. (2019). Redesigning systems to improve teamwork and quality for hospitalized patients (RESET): study protocol evaluating the effect of mentored implementation to redesign clinical microsystems. BMC health services research, 19, 293. https://doi.org/10.1186/s12913-019-4116-z

54. Olds, D. M., Aiken, L. H., Cimiotti, J. P., \& Lake, E. T. (2017). Association of nurse work environment and safety climate on patient mortality: a cross-sectional study. International Journal of Nursing Studies, 74, 155-161. https://doi.org/10.1016/j.ijnurstu.2017.06.004

55. Paguio, J. T., \& Doris, Y. S. F. (2019). A mixed methods study to evaluate the 
effects of a teamwork enhancement and quality improvement initiative on nurses' work environment. Journal of Advanced Nursing, https://doi.org/10.1111/jan.14270

56. Pavan, N. F. P., Magalhães, A. L. P., Poncio, D. F., Ascari, R. A., Zanini, P. D., da Silva Knihs, N., \& Silva, O. M. (2019). Patient safety culture in kidney transplant patients in western Santa Catarina. Acta Paulista de Enfermagem, 32(4), 398-405. http://dx.doi.org/10.1590/1982-0194201900055

57. Pham J. C., Aswani M. S., \& Rosen M. (2012). Reducing medical errors and adverse events. Annual Reviews of Medicine, 63, 447-463. https://doi.org/10.1146/annurev-med-061410-121352

58. Profit, J., Etchegaray, J., Petersen, L. A., Sexton, J. B., Hysong, S. J., Mei, M., \& Thomas, E. J. (2012). The Safety Attitudes Questionnaire as a tool for benchmarking safety culture in the NICU. Archives of Disease in Childhood, 97(2), F127-32. http://dx.doi.org/10.1136/archdischild-2011-300612

59. Profit, J., Sharek, P. J., Amspoker, A. B., Kowalkowski, M. A., Nisbet, C. C., Thomas, E. J., Chadwick, W. A., \& Sexton, J. B. (2014). Burnout in the NICU setting and its relation to safety culture. BMJ Quality \& Safety, 23(10), 806-813. http://dx.doi.org/10.1136/bmjqs-2014-002831

60. Profit, J., Sharek, P. J., Kan, P., Rigdon, J., Desai, M., Nisbet, C. C., Tawfik, D. S., Thomas, E. J., Lee. H. C., \& Sexton, J. B. (2017). Teamwork in the NICU setting and its association with healthcare-associated infections in very low birth weight infants. American Journal of Perinatology, 34(10), 1032-1040. http://dx.doi.org/10.1055/s-0037-1601563

61. Roney, L. N., \& Acri, M. C. (2018). The cost of caring: an exploration of compassion fatigue, compassion satisfaction, and job satisfaction in pediatric nurses. Journal of Pediatric Nursing, 40, 74-80. http://dx.doi.org/10.1016/j.pedn.2018.01.016

62. Saltzman, R., Roeder, T., Lambton, J., Param, L., Frost, B., \& Fernandes, R. (2017). The impact of a discharge holding area on the throughput of a pediatric unit. Service Science, 9(2), 121-135. https://doi.org/10.1287/serv.2016.0167

63. Schepers, P., \& Van den Berg, P. T., (2007). Social factors of work-environment creativity. Journal of Business and Psychology, 21(3), 407-428. https://doi.org/10.1007/s10869-006-9035-4

64. Sexton J. B., Helmreich R. L., Neilands T. B., Rowan K., Vella K., Boyden J., Roberts P. R., Thomas E. J., (2006). The safety attitudes questionnaire: Psychometric properties, benchmarking data, and emerging research. BMC Health Service Research, 6, 44. https://doi.org/10.1186/1472-6963-6-44.

65. Sexton, J. B., Adair, K. C., Leonard, M. W., Frankel, T. C., Proulx, J., Watson, S. 
R., ... \& Frankel, A. S. (2018). Providing feedback following Leadership WalkRounds is associated with better patient safety culture, higher employee engagement and lower burnout. BMJ Quality \& Safety, 27(4), 261-270. http://dx.doi.org/10.1136/bmjqs-2016-006399

66. Sexton, J. B., Schwartz, S. P., Chadwick, W. A., Rehder, K. J., Bae, J., Bokovoy, J., ... \& Profit, J. (2017). The associations between work-life balance behaviours, teamwork climate and safety climate: cross-sectional survey introducing the worklife climate scale, psychometric properties, benchmarking data and future directions. BMJ Quality \& Safety, 26(8), 632-640. http://dx.doi.org/10.1136/bmjqs-2016-006032

67. Tawfik, D. S., Sexton, J. B., Kan, P., Sharek, P. J., Nisbet, C. C., Rigdon, J., Lee, H.C., \& Profit, J. (2017). Burnout in the neonatal intensive care unit and its relation to healthcare-associated infections. Journal of Perinatology, 37(3), 315-320. https://doi.org/10.1038/jp.2016.211

68. Vikström, S., \& Johansson, K. (2019). Professional pride: a qualitative descriptive study of nursing home staff's experiences of how a quality development project influenced their work. Journal of Clinical Nursing, 28(15-16), 2760-2768. https://doi.org/10.1111/jocn.14884

69. Wagner, A., Hammer, A., Manser, T., Martus, P., Sturm, H., \& Rieger, M. (2018). Do occupational and patient safety culture in hospitals share predictors in the field of psychosocial working conditions? Findings from a cross-sectional study in German university hospitals. International Journal of Environmental Research and Public Health, 15(10), 2131. https://doi.org/10.3390/ijerph15102131

70. Winning, A. M., Merandi, J. M., Lewe, D., Stepney, L., Liao, N. N., Fortney, C. A., \& Gerhardt, C. A. (2018). The emotional impact of errors or adverse events on healthcare providers in the NICU: the protective role of coworker support. Journal of Advanced Nursing, 74(1), 172-180. https://doi.org/10.1111/jan.13403

71. Wu, C. F., Wu, H. H., Lee, Y. C., \& Huang, C. H. (2019). What attributes determine overall satisfaction in patient safety culture? An empirical study of the perceptions of hospital staff in Taiwan. Journal of Testing and Evaluation, 49(1). https://doi.org/10.1520/JTE20180713

72. Wu, Y., Fujita, S., Seto, K., Ito, S., Matsumoto, K., Huang, C. C., \& Hasegawa, T. (2013). The impact of nurse working hours on patient safety culture: a crossnational survey including Japan, the United States and Chinese Taiwan using the Hospital Survey on Patient Safety Culture. BMC Health Services Research, 13, 394. https://doi.org/10.1186/1472-6963-13-394

73. Zheng, S., Tucker, A. L., Ren, Z. J., Heineke, J., McLaughlin, A., \& Podell, A. L. (2018). The impact of internal service quality on preventable adverse events in 
hospitals. Production and Operations Management, 27(12), 2201-2212. https://doi.org/10.1111/poms.12758 
Table 1: The Safety Attitudes Questionnaire

\begin{tabular}{|c|c|}
\hline Teamwork & (1) Nurse input is well received in this clinical area \\
\hline (TC) & $\begin{array}{l}\text { (2) In this clinical area, it is difficult to speak up if I perceive a problem } \\
\text { with patient care }{ }^{(r)}\end{array}$ \\
\hline & $\begin{array}{l}\text { (3) Disagreements in this clinical area are resolved appropriately (i.e. } \\
\text { not who is right, but what is best for the patient) }\end{array}$ \\
\hline & (4) I have the support I need from other personnel to care for patients \\
\hline & $\begin{array}{l}\text { (5) It is easy for personnel here to ask questions when there is something } \\
\text { that they do not understand }\end{array}$ \\
\hline & $\begin{array}{l}\text { (6) The physicians and nurses here work together as a well-coordinated } \\
\text { team }\end{array}$ \\
\hline Safety climate & (7) I would feel safe being treated here as a patient \\
\hline (SC) & (8) Medical errors are handled appropriately in this clinical area \\
\hline & $\begin{array}{l}\text { (9) I know the proper channels to direct questions regarding patient } \\
\text { safety in this clinical area }\end{array}$ \\
\hline & (10) I receive appropriate feedback about my performance \\
\hline & (11) In this clinical area, it is difficult to discuss errors ${ }^{(r)}$ \\
\hline & $\begin{array}{l}\text { (12) I am encouraged by my colleagues to report any patient safety } \\
\text { concerns I may have }\end{array}$ \\
\hline & $\begin{array}{l}\text { (13) The culture in this clinical area makes it easy to learn from the } \\
\text { errors of others }\end{array}$ \\
\hline Job satisfaction & (14) I like my job \\
\hline (JS) & (15) Working here is like being part of a large family \\
\hline & (16) This is a good place to work \\
\hline & (17) I am proud to work in this clinical area \\
\hline & (18) Morale in this clinical area is high \\
\hline $\begin{array}{l}\text { Stress recognition } \\
\text { (SR) }\end{array}$ & $\begin{array}{l}\text { (19) When my workload becomes excessive, my performance is } \\
\text { impaired }^{(r)}\end{array}$ \\
\hline & (21) I am less effective at work when tired ${ }^{(r)}$ \\
\hline & $\begin{array}{l}\text { (25) I am more likely to make errors in tense or hostile situations (e.g. } \\
\text { emergency resuscitation, seizure) }{ }^{(r)}\end{array}$ \\
\hline & (26) Fatigue impairs my performance during emergency situations ${ }^{(r)}$ \\
\hline Perceptions & (27) Managers supports my daily efforts \\
\hline management & (28) Managers do not knowingly compromise patient safety \\
\hline (PM) & $\begin{array}{l}\text { (29) I get adequate, timely information about events that might affect } \\
\text { my work }\end{array}$ \\
\hline & $\begin{array}{l}\text { (30) The levels of staffing in this clinical area are sufficient to handle } \\
\text { the number of patients }\end{array}$ \\
\hline Working conditions & (31) Problem personnel are dealt with constructively \\
\hline$(\mathrm{WC})$ & (32) This hospital does a good job at training new personnel \\
\hline & $\begin{array}{l}\text { (33) All the necessary information for diagnostic and therapeutic } \\
\text { decisions is routinely available to me }\end{array}$ \\
\hline & (34) Trainees in my discipline are adequately supervised \\
\hline
\end{tabular}




\begin{tabular}{ll}
\hline Emotional exhaustion & (20) I feel like I'm at the end of my rope ${ }^{(\mathrm{r})}$ \\
(EE) & (22) I feel burned out from my work ${ }^{(\mathrm{r})}$ \\
& (23) I feel frustrated by my job \\
& (24) I feel I'm working too hard on my job \\
& (35) I feel emotionally exhausted from my work \\
& (36) I feel used up at the end of the workday \\
& (37) I feel tired when I get up in the morning and have to face another \\
& day on the job \\
& (38) Working with people all day is really a strain for me ${ }^{(\mathrm{r})}$ \\
& (39) Working with people directly puts too much stress on me ${ }^{(\mathrm{r})}$ \\
\hline Work-life balance & (40) Missed meals \\
(WLB) & (41) A hasty meal \\
(4 point frequency & (42) All-day work without any rest \\
scale) & (43) Individual or family plan changes due to work factors \\
& (44) Poor sleep \\
& (45) Less than five-hours of sleep at night \\
& (46) Working overtime
\end{tabular}

Note: (r): reverse scored questions 
Table 2: Demographic characteristics of pediatric nurses

\begin{tabular}{|c|c|c|c|}
\hline \multicolumn{2}{|c|}{ DEMOGRAPHIC VARIABLE } & Frequency & Percentage \\
\hline \multirow{2}{*}{ Gender } & Male & 1 & 0.6 \\
\hline & Female & 154 & 99.4 \\
\hline \multirow{4}{*}{ Age } & 21-30 years old & 55 & 35.5 \\
\hline & $31-40$ years old & 59 & 38.1 \\
\hline & $41-50$ years old & 34 & 21.9 \\
\hline & 51-60 years old & 7 & 4.5 \\
\hline \multirow{2}{*}{ Supervisor/Manager } & Yes & 10 & 6.5 \\
\hline & No & 145 & 93.5 \\
\hline Respondents & No & 115 & 74.2 \\
\hline reporting adverse & $1-5$ & 38 & 24.5 \\
\hline $\begin{array}{l}\text { events in the past } 12 \\
\text { months }\end{array}$ & $6-10$ & 2 & 1.3 \\
\hline \multirow{3}{*}{ Education } & Senior High School & 1 & 0.6 \\
\hline & College/University & 139 & 89.7 \\
\hline & Master's Degree & 15 & 9.7 \\
\hline \multirow{6}{*}{$\begin{array}{l}\text { Working experience } \\
\text { in organization }\end{array}$} & Less than 1 year & 8 & 5.2 \\
\hline & 1 to 2 years & 9 & 5.8 \\
\hline & 3 to 4 years & 20 & 12.9 \\
\hline & 5 to 10 years & 34 & 21.9 \\
\hline & $11-20$ years & 65 & 41.9 \\
\hline & 21 years and above & 19 & 12.3 \\
\hline \multirow{6}{*}{$\begin{array}{l}\text { Working experience } \\
\text { in position }\end{array}$} & Less than 1 year & 9 & 5.8 \\
\hline & 1 to 2 years & 10 & 6.5 \\
\hline & 3 to 4 years & 18 & 11.6 \\
\hline & 5 to 10 years & 35 & 22.6 \\
\hline & $11-20$ years & 69 & 44.5 \\
\hline & 21 years and above & 14 & 9 \\
\hline
\end{tabular}


Table 3: Characteristics of patient safety variables $(n=155)$

\begin{tabular}{|l|l|l|l|l|}
\hline Variables/Dimensions & Max. & Mean (\% score) & SD & $\alpha$ \\
\hline Safety climate & 35.00 & $26.59(76 \%)$ & 3.734 & 0.760 \\
\hline Emotional exhaustion & 44.00 & $23.88(54 \%)$ & 7.338 & 0.926 \\
\hline Job satisfaction & 25.00 & $20.01(80 \%)$ & 3.754 & 0.940 \\
\hline Teamwork climate & 27.00 & $22.34(83 \%)$ & 3.120 & 0.680 \\
\hline Stress recognition & 20.00 & $14.38(72 \%)$ & 3.784 & 0.925 \\
\hline Perceptions of management & 20.00 & $15.75(79 \%)$ & 2.966 & 0.860 \\
\hline Working conditions & 20.00 & $15.90(80 \%)$ & 2.935 & 0.917 \\
\hline
\end{tabular}

Table 4 ANOVA Results for Nurse's Age in Seven Dimensions

\begin{tabular}{|l|l|l|l|}
\hline Dimension & F & Sig. & Bonferroni \\
\hline Safety climate & 1.579 & .197 & \\
\hline Emotional exhaustion & 5.001 & .002 & $21-30>51-60 ; 31-40>51-60$ \\
\hline Job Satisfaction & 1.941 & .125 & \\
\hline Teamwork climate & 2.678 & .049 & $51-60>31-40$ \\
\hline Stress Recognition & 1.390 & .248 & \\
\hline Perceptions of Management & 2.056 & .108 & \\
\hline Working Conditions & 3.459 & .018 & $51-60>21-30 ; 51-60>31-40$ \\
\hline
\end{tabular}

Table 5: Pearson's $\rho$ of patient safety variables

\begin{tabular}{|l|r|r|r|l|l|l|l|}
\hline \multirow{2}{*}{ Variables } & \multicolumn{6}{l}{ Pearson's $\rho$} & \multicolumn{1}{l|}{} \\
\cline { 2 - 8 } & SC & EE & JS & TC & SR & PM & WC \\
\hline SC & 1.000 & & & & & & \\
\hline EE & $-.301^{* *}$ & 1.000 & & & & & \\
\hline JS & $.724^{* *}$ & $-.424^{* *}$ & 1.000 & & & & \\
\hline TC & $.761^{* *}$ & $-.315^{* *}$ & $.717^{* *}$ & 1.000 & & & \\
\hline SR & $.321^{* *}$ & .078 & $.320^{* *}$ & $.287^{* *}$ & 1.000 & & \\
\hline PM & $.711^{* *}$ & $-.423^{* *}$ & $.804^{* *}$ & $.749^{* *}$ & $.269^{* *}$ & 1.000 & \\
\hline WC & $.714^{* *}$ & $-.350^{* *}$ & $.759^{* *}$ & $.694^{* *}$ & $.302^{* *}$ & $.855^{* *}$ & 1.000 \\
\hline
\end{tabular}

Note: ${ }^{* *}$ p-value $<0.01$; SC: safety climate; EE: emotional exhaustion; JS: job satisfaction; TC: teamwork climate; SR: stress recognition; PM: perceptions of management; WC: working conditions 
Table 6. Multiple linear regression - safety climate (response variable), emotional exhaustion and job satisfaction (explanatory variables)

\begin{tabular}{|c|c|c|c|c|c|c|}
\hline \multirow[t]{2}{*}{ Response variables } & \multirow{2}{*}{$\begin{array}{l}\text { Explanatory } \\
\text { variables }\end{array}$} & \multirow[t]{2}{*}{ Coefficient } & \multicolumn{2}{|c|}{$95 \% \mathrm{CI}$} & \multirow[t]{2}{*}{ Sig. } & \multirow[t]{2}{*}{$\mathrm{R}^{2}$} \\
\hline & & & LL & UL & & \\
\hline \multirow[t]{3}{*}{ Model $^{*}$ Safety climate } & Teamwork climate & 0.505 & 0.443 & 0.767 & 0.007 & \multirow[t]{3}{*}{0.688} \\
\hline & Working conditions & 0.204 & 0.084 & 0.435 & $<0.001$ & \\
\hline & Job satisfaction & 0.208 & 0.057 & 0.357 & 0.004 & \\
\hline
\end{tabular}

*Explanatory variables: emotional exhaustion, job satisfaction, teamwork climate, stress recognition, perceptions of management, working conditions. 